\title{
The Bridge House: A Living Dynamics Laboratory
}

Dr. Graham C. Archer P.Eng, Cal Poly San Luis Obispo

Dr. Cole C McDaniel, California Polytechnic State University

Dr. Cole McDaniel is an associate professor of Architectural Engineering at the California Polytechnic State University.

Mr. Pablo D. Ramos 


\section{The Bridge House: A Living Dynamics Laboratory}

In 1965, a class of undergraduate students ${ }^{3}$ launched a project to utilize the rough terrain surrounding their local campus. Their solution was to span a ravine with a bridge-like structure (Figure 1) similar to that of Mies Van Der Rohe's Glass House. Over the years, the building has mostly been forgotten and has fallen into a state of disrepair. Fortunately, in 2011 another team of students ${ }^{8}$ took on the task of revitalizing the building and has created a living structural dynamics laboratory. The relatively small building has a clearly visible structural system that lends itself to rapid analysis by undergraduate students. By positioning small $(<100 \mathrm{lb})$ shaking devices at various locations on the floor and at two predetermined ceiling mounts, the students can explore the actual dynamic behavior of the structure through standard accelerometers, common data acquisition hardware and some custom software. Comparison of the student's predictions using hand calculations and increasingly advanced computational modeling with the actual structural response has been found to have several benefits. Students not only sharpen their modeling skills, they can explore the accuracy of their modeling assumptions and learn a healthy skepticism for computational results.
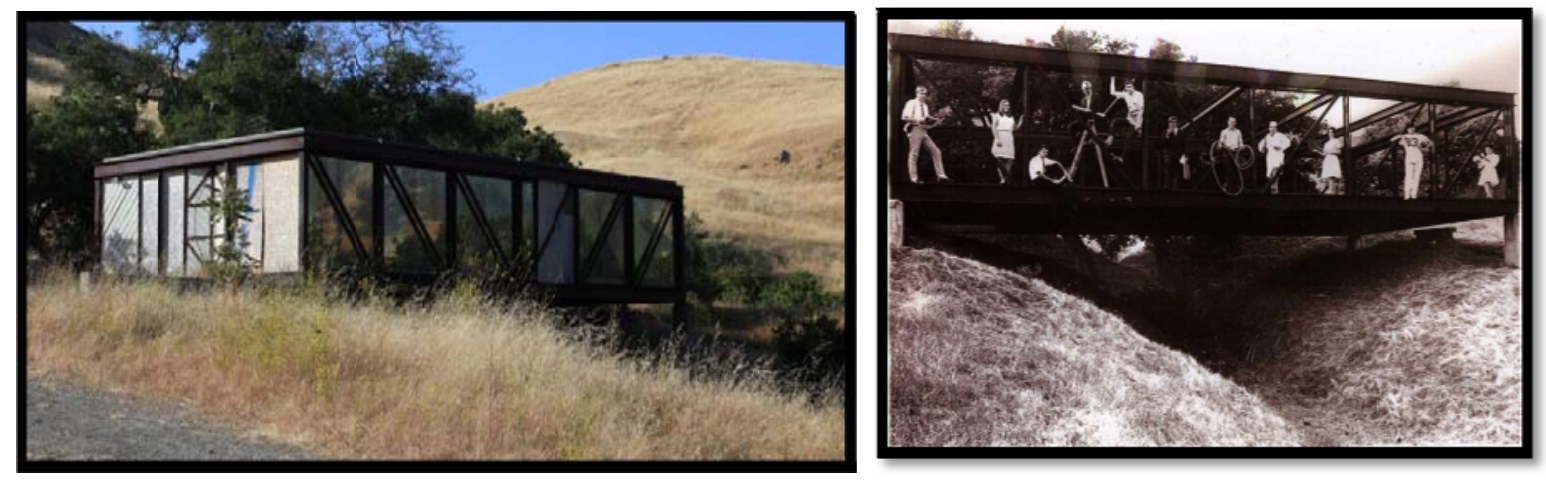

Figure 1: The Bridge House $e^{8,3}$

While simple, the structure possesses several interesting structural features, the first of which are removable braces (supplementing moment-resisting frames). This permits the exploration of system identification and damage detection exercises. Furthermore, the removable braces are tuned such that in some configurations, the natural frequencies of two modes collide. With this, the students can explore mode coupling and the beating phenomenon. Students can also explore both rigid and flexible diaphragms using the roof diaphragm alone. With the braces removed on one or two parallel walls, the bare steel roof deck exhibits distortions in some modes yet remains rigid in others. In addition to these features, students can explore the attachment of the diaphragms to the steel beams, the presence of physically discernible vertical vibrations, and a shift in modal frequencies due to thermal effects.

This paper presents both the layout and configuration of the physical structure including the removable braces, flexible foundations, diaphragm attachment, and the associated structural dynamic behavior. It also details the use of the shaking devices employed to excite the building 
structure and the software and hardware necessary to obtain the building response. Most importantly the concepts and execution of the learning modules for the student exploration of structural dynamics are presented. The learning modules, hardware, and software have been customized for the Bridge House structure, but are equally adaptable to any small structure (up to and including 3-story lecture halls) on campuses nationwide.

\section{The Structure}

The Bridge House is a one-story steel structure with a lateral force resisting system (LFRS) composed of ordinary moment frames (and removable braces) in the north-south (NS) direction and braced frames in the east-west (EW) direction. The structure is similar to that of a bridge truss and spans $48 \mathrm{ft}$ in the longitudinal direction and $24 \mathrm{ft}$ in the transverse direction. The columns and braces on the exterior of the building are hollow structural sections that are welded in between two channels which comprise the chord members of the truss system. The roof is made up of rigid insulation topped with gravel-on-metal deck supported by steel beams (Figure 2). The floor is composed of $31 / 2$ - inch thick lightweight concrete also on metal deck supported by steel beams. There is no visible physical connection between the roof deck panels. It is assumed that the roof deck panels and roof beams are interconnected through intermediate spot welds. The structure rests on four 18” square concrete piers.
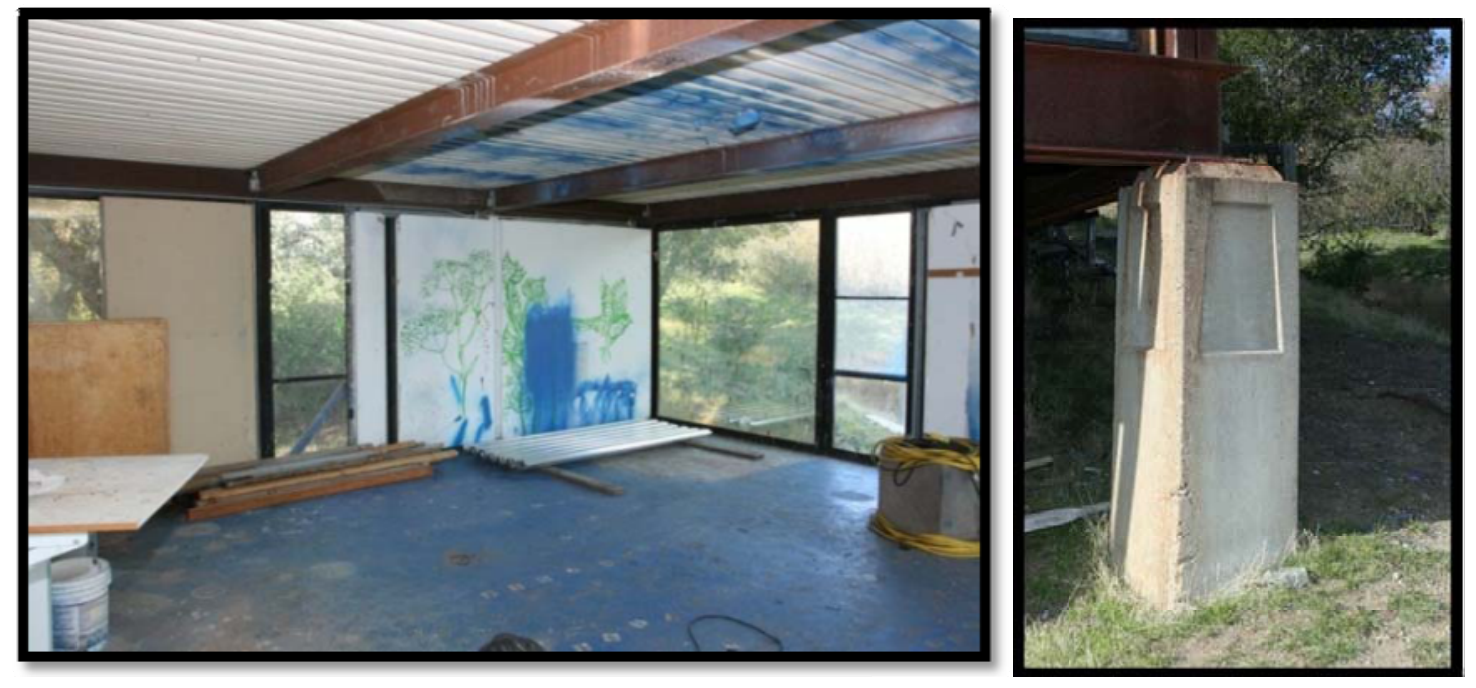

Figure 2: Interior View of Roof Diaphragm and Exterior View of a Pier ${ }^{8}$

The structure is located within walking distance of the main campus and has been falling into a state of disrepair. Recently a group of undergraduate students took on the task of revitalizing the structure and have turned it into a living structural dynamics laboratory. Instead of having the structure house laboratory apparatus and specimens, the structure itself has become the laboratory. Students will study structural dynamics by testing the building structure through ambient and forced vibration testing methods. 


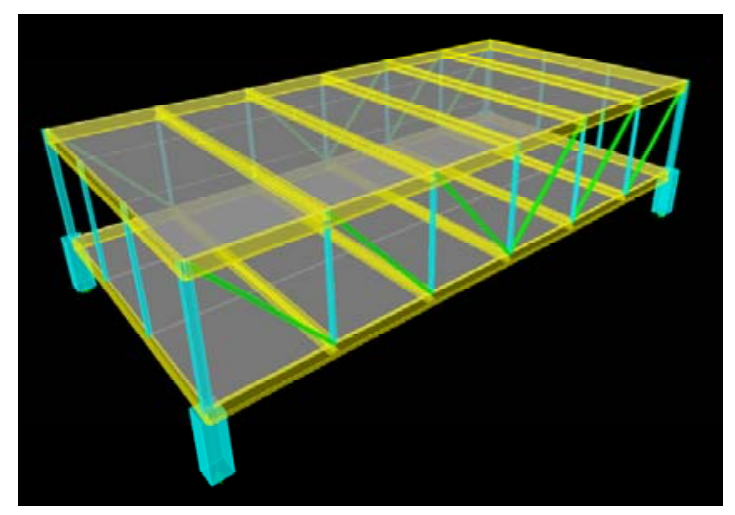

Figure 3: Student Computational Model $^{8}$

The first task the students accomplish is to produce a computation model of the structure based on a simplified set up plans and a quick site visit. At this stage in their education (UG Seniors close to graduation) they have taken a matrix structural analysis course, an introductory structural dynamics course, and at least two design courses. Thus they can rapidly model the small structure and predict the natural frequencies and mode shapes within a few hours work. It is however in the subsequent physical testing of the structure, the students learn of the maturity of the their modeling skills

\section{Ultra-Low Forced Vibration Testing}

The authors have developed and implemented ${ }^{5,6,7}$ a new concept in Forced Vibration Testing (FVT) for low-rise building structures using ultra-low force amplitudes. Using low-cost equipment ( $<\$ 15,000$ in total) that can be easily transported on a hand-cart by one person, the authors have successfully applied this Ultra-Low FVT (UL-FVT) to 14 different building structures to obtain the natural periods, mode shapes and equivalent viscous damping ratios. The testing is accomplished by placing a small portable ( 100 lb) harmonic shaker (see Figure 4) on the upper floors of the building and recording the resulting floor accelerations throughout the structure using highly sensitive accelerometers and sophisticated data acquisition software. In each of the 14 low-rise buildings tested to date, the mode shapes and periods compared well with computational model predictions.

The building structures tested to date include steel and concrete moment resisting frames, steel concentric braced frames, reinforced concrete moment resisting frames, and reinforced concrete shear walls ${ }^{11}$. The majority of the structures were rectangular or L-shaped 2 and 3 story oncampus buildings around $20,000 \mathrm{ft}^{2}$ of floor space ${ }^{4}$. The largest structure tested to date is a 5story $180,000 \mathrm{ft}^{2}$ library building ${ }^{10}$. 


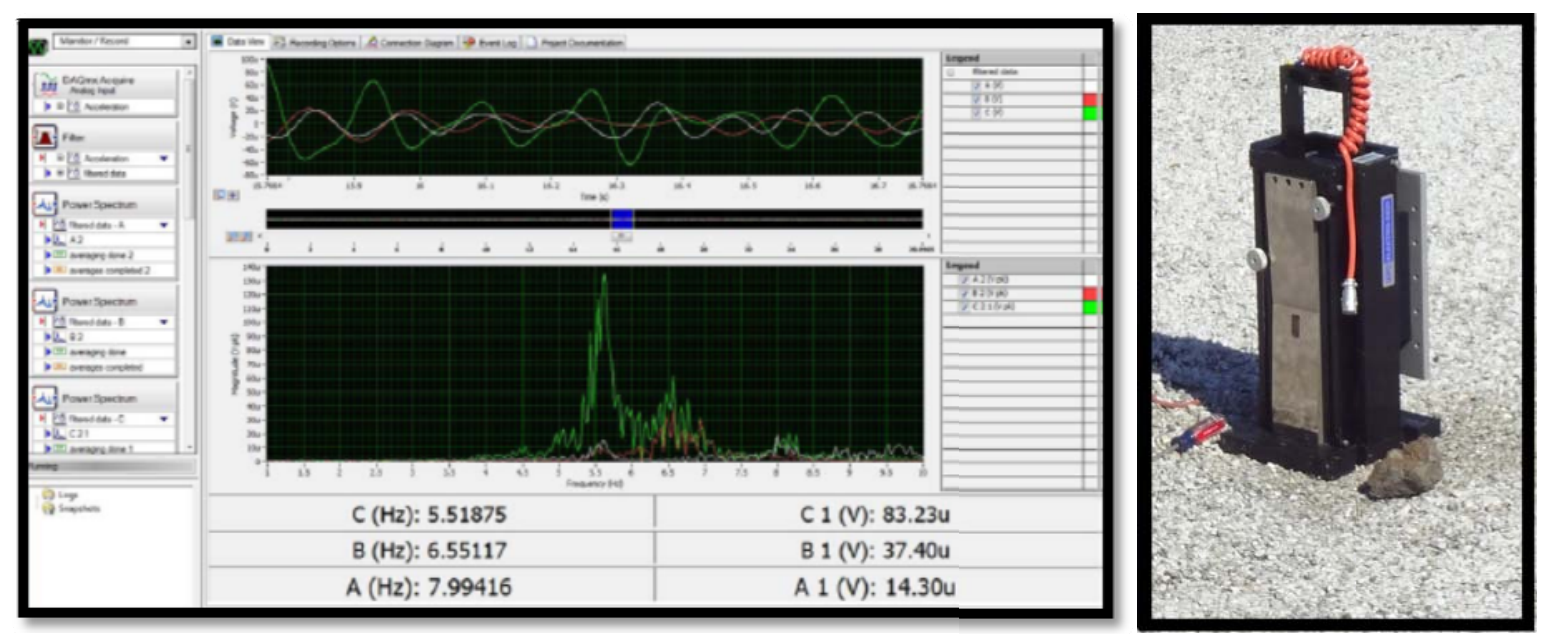

Figure 4: Accelerometer Output Screen and Shaker (in a vertical layout) ${ }^{8,9}$

When the shaker is left oscillating, its effect is detectible above the ambient noise throughout all floors in the building. When the shaker's frequency is set to match one of the structure's natural frequencies, the building accelerations at that frequency become obvious. Thus armed with the little shaker, three accelerometers and a data acquisition system, the authors created the UL-FVT method. The ability of a $30 \mathrm{lb}$ harmonic load to produce detectable accelerations throughout a low-rise building structure is entirely predicted by theory. As reported in the authors' student Master's thesis, the predicted floor accelerations for a 2-story, 20,000 ft ${ }^{2}, 2,000$ ton campus building can be determined using computationally derived mode shapes. With a $30 \mathrm{lb}$ harmonic load applied at the centroid of the 2nd floor, the predicted peak floor accelerations nearby are $212 \mu \mathrm{g}^{11}$. When measured experimentally, the floor accelerations were found to be $231 \mu \mathrm{g}$. In general, the theoretical and experimental accelerations have been found to be within 5\% of each other. As a means of comparison, the accelerometers used in the UL-FVT method have a published resolution of 1-2 $\mu \mathrm{g}$. Ambient vibrations are generally in the 2-25 $\mu \mathrm{g}$ range. Thus the UL-FVT shaker and accelerometers are quite capable of producing detectible building accelerations. For a structure as small as the Bridge House $\left(1100 \mathrm{ft}^{2}\right)$ at resonance the shaker can produce accelerations far in excess of these values and are readily felt without the use of any equipment.

\section{Natural Frequencies and Damping Modules}

The first experiment test module the students explore is an ambient vibration test to estimate the natural frequencies of the building. For this, three accelerometers are employed; one in the NS direction, one in the EW direction and one placed vertically. By placing the accelerometers in a variety of places on the floor and on the exposed beams of the roof, the students not only see the likely frequencies of vibration, they start to gain an understanding of the magnitude of the vibrations and thus a general idea of the nature of the mode shapes associated with the natural frequency. It is at this point that the students start to question the validity of their computational models. Some observe that their predicted frequencies and direction of the mode shapes differ dramatically from those observed. In general, the students tend to believe their computational models and often blame the discrepancy on the random nature of ambient vibrations. 
At this point, the students bring out the shaker and start to work through a series of forced vibration testing modules. Either from the ambient test data or the student's computational predictions, the students select a mode to explore and set the shaker vibrating in the direction of the mode shape and at the location of maximum displacement predicted for the mode shape. The three accelerometers are placed somewhat randomly in any location which also will experience significant displacements according to the mode shape. By adjusting the output frequency of the shaker and recording the resulting primary acceleration of the structure, the students can rapidly determine (see Figure 5) one or more of the natural frequencies of the building. If their predictions are significantly off reality, this process may take a little longer.

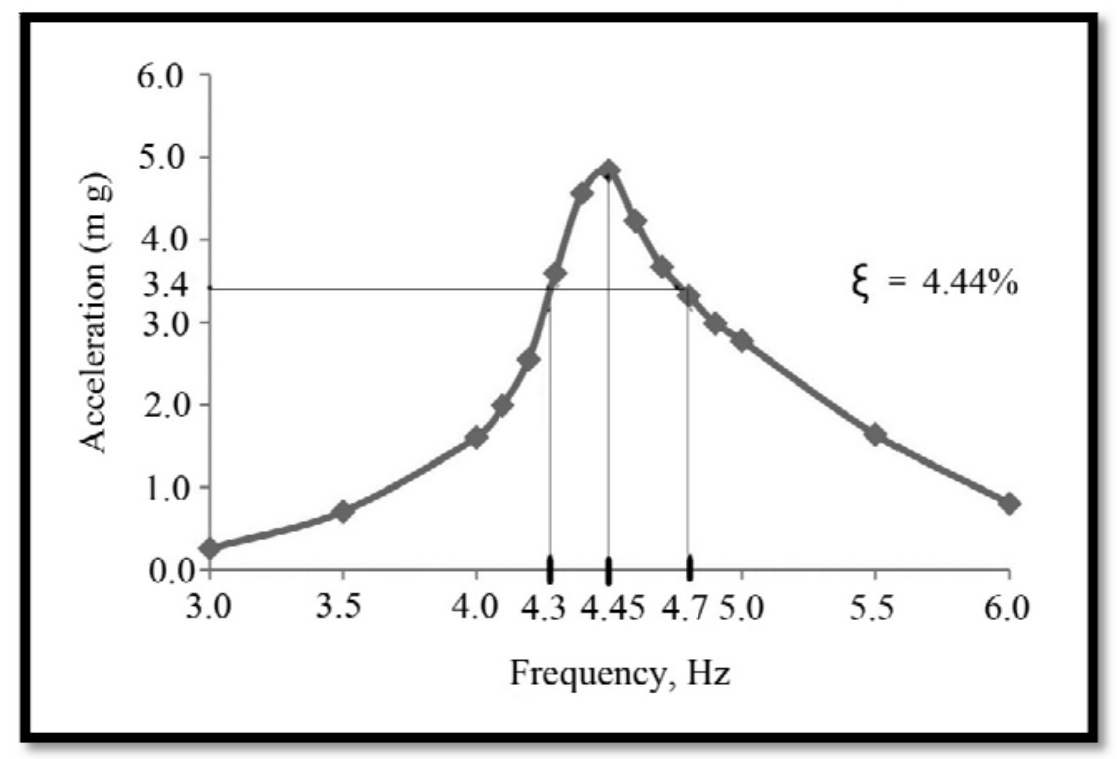

Figure 5: Typical Frequency Response ${ }^{9}$

Also shown in Figure 5 is the student result of the Equivalent Viscous Damping Module. As the students hone in on the natural frequency they produce the frequency response graph. Their next task is to use the Half-Power-Band Method $^{2}$ to predict the equivalent viscous damping for the mode and compare it to typical values used in design. The students also observe the logarithmic decay of the motion after the shaker is turned off in order to further demonstrate the damping phenomenon. It is interesting to note that although this subject has been covered in both lectures and assignments, it is often only after the students perform this test on a real structure that they begin to understand the concept.

\section{Mode Shapes}

Once a given natural frequency and equivalent viscous damping is obtained, the students move on to the Mode Shape Module. By leaving the shaker vibrating at the natural frequency from the previous module the entire structure vibrates primarily in the mode shape associated with the given frequency. Of course all the other mode shapes will contribute slightly. However for lightly damped structures, this contribution is minimal. Thus the mode shape can be mapped by the students by placing the accelerometers at pre-determined locations on the floor and underside 
of the roof beams. A sample of student mode shapes for the first three vertical modes and the first two transverse modes is shown in Figure 6.
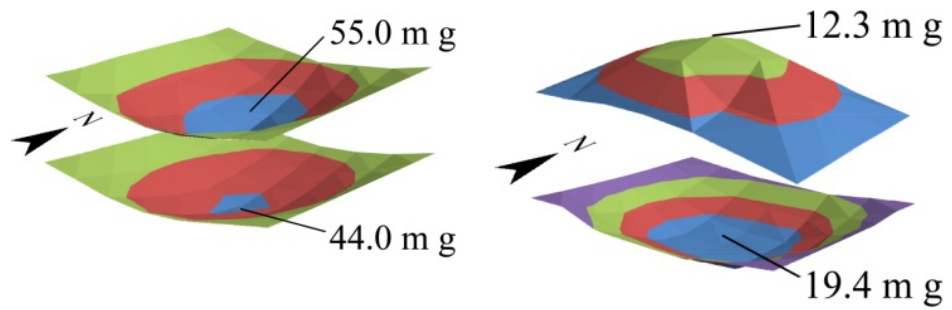

(a)

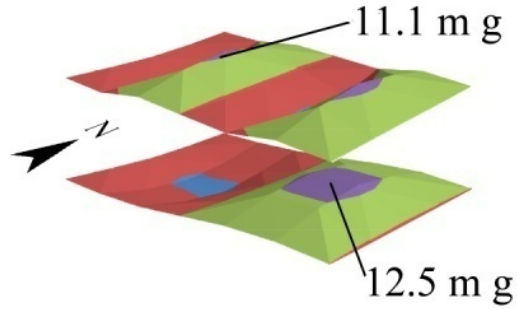

$12.5 \mathrm{~m} \mathrm{~g}$

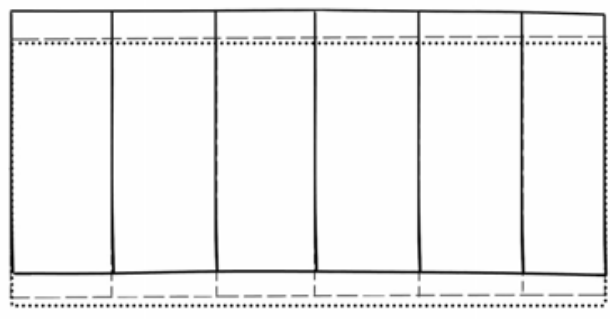

(b)

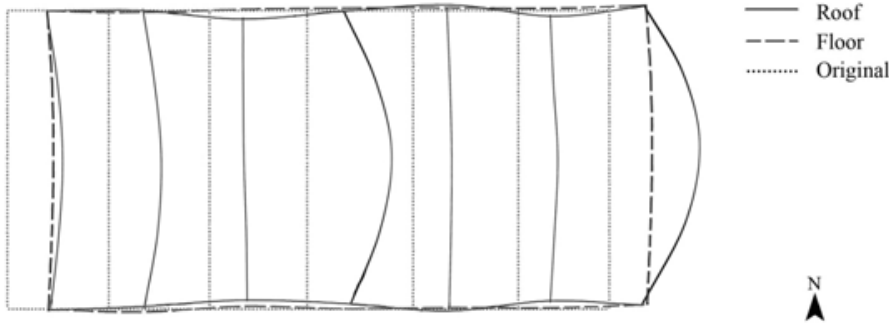

(c)

Figure 6: (a) 1st Three Vertical Mode Shapes;Plan View of the (b) NS and (c) EW Mode Shape ${ }^{9}$

The magnitudes of the vertical accelerations shown in Figure 6 give rise to an interesting exercise. The accelerations are comparatively large and easily felt. In fact some students find the vibrations a little disturbing. With the structure vibrating in the first vertical mode, shown in the upper left-hand corner, the students can walk across the floor and feel the mode shape firsthand. Switching to the third vertical mode shown in the upper right hand of Figure 6, when the students walk across the floor they can feel the node (the point of zero vibration) at the centre of the floor. The students have reported that this exercise has greatly increased their appreciation of structural mode shapes. Armed with the experimentally determined frequencies and mode shapes, the students are confronted with the discrepancies between the building behavior and their computational model predictions. The students then explore their models and often find incorrect member sizes, orientations, connectivity, and mass modeling errors. At the end of the modules their modeling skills are demonstratively better and they have developed a healthy skepticism of computational results.

\section{Diaphragm Modeling Module}

The two transverse modes shown at the bottom of Figure 6 are the subject of the Diaphragm Modeling Module that is generally reserved for more advanced undergraduate or master's students. The NS mode is essentially a rigid body motion and agrees well with student modeling assumptions of a rigid diaphragm. However the first EW mode shows flexible behavior even though the span that is flexing is half as long as it is for the NS mode. The reason does not become obvious until the students realize that in the EW direction the structure is braced whereas in the EW direction lateral motions are resisted by a flexible moment frame. Thus in the EW direction, the diaphragm is flexible relative to the braced frame. 


\section{Advanced Modules}

The east and west walls of the Bridge House have been outfitted with removable braces shown in Figure 7. The HSS section can float freely between the channels or can rapidly be shimmed and bolted forming a braced frame. It takes less than 5 minutes to bolt or unbolt the brace. As one might expect, the presence or absence of the brace in the moment frame greatly affects the natural frequencies and modes shapes of the structure. Once the advanced students have a reasonably accurate model of the structure they are instructed to place braces in their models and produce new predictions of dynamic properties.
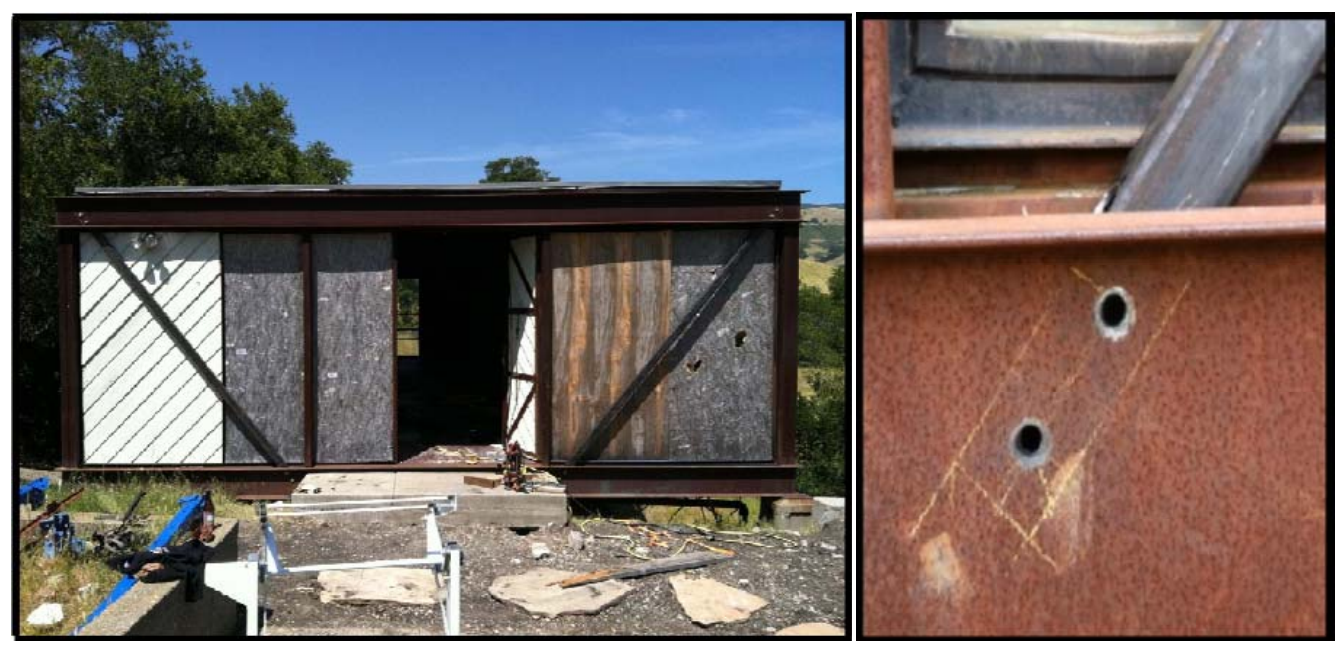

Figure 7: Removable Braces and Connection Detail ${ }^{8}$

The students then make the same bracing changes in the actual building and repeat the forced vibration testing to determine the natural frequencies and mode shapes. A typical frequency shift is shown in Figure 8.

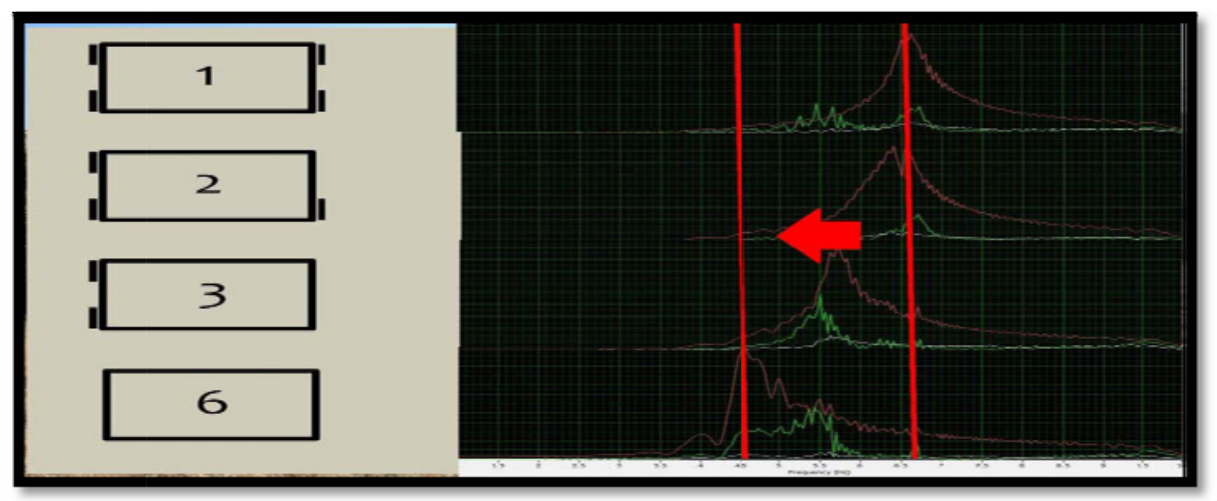

Figure 8: Frequency Shift for Various Brace Configurations ${ }^{8}$

The left hand side of Figure 8 shows the brace configuration and the right hand side shows the ambient vibrations in the frequency domain. As braces are removed and hence the structure becomes more flexible, the dominant NS natural frequency shifts lower. By calculating the 
Modal Assurance Criterion (MAC) ${ }^{1}$ number, a statistical indicator of consistency between their predicted mode shapes for a variety of bracing configurations and the experimental results for a given bracing configuration, the students can use their computational models to predict the bracing configuration used in the building. This introduces the students to the concept of damage detection.

The Bridge House exhibits an odd shift in the natural frequencies that has been determined to be related to the surface temperature of the exposed structural steel. As the temperatures rise, the natural frequencies shift slight lower (see Figure 9). Since the mass of the structure is unchanged the stiffness of the structure must decrease as the temperature increases. This is a puzzling result for the students and faculty alike until one realizes that as a member heats up it tries to expand against the rest of the structure and its supports. This restraint causes compressive forces in the member and thus through the P-delta effect, the flexural stiffness of the member decreases. Students are asked to replicate the effect by performing a P-delta analysis of the structure with a thermal increase in the steel members on one side of the structure.

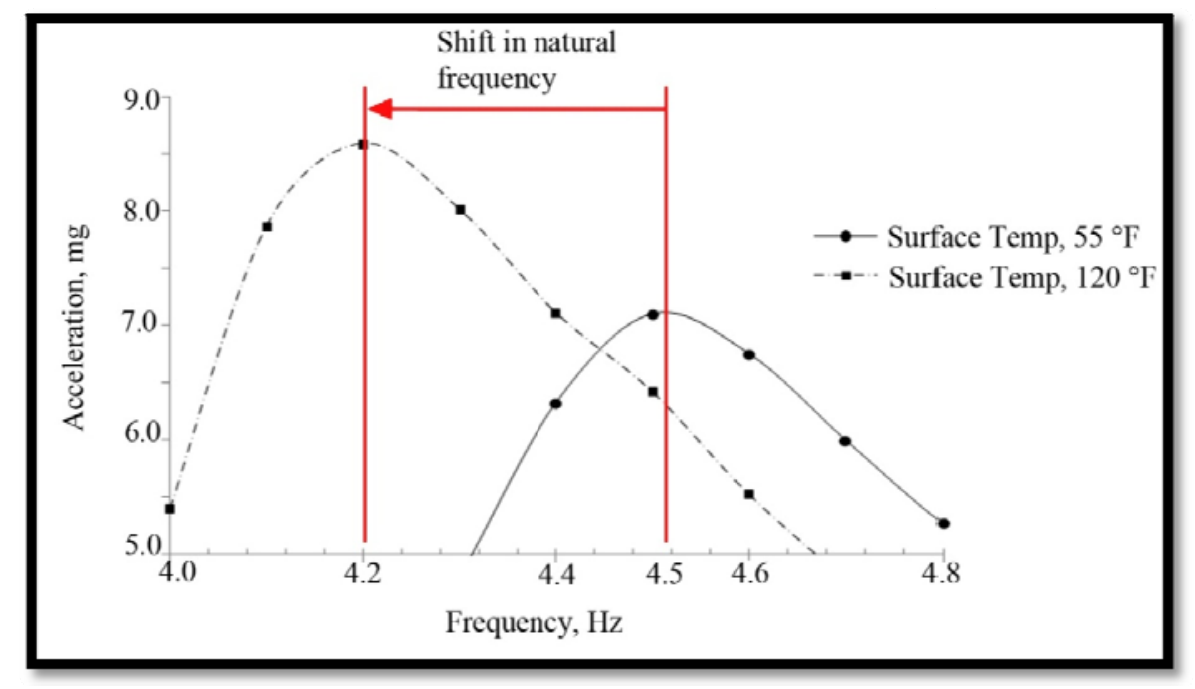

Figure 9: Frequency Shift Due to Thermal Effects ${ }^{9}$

\section{Conclusions}

The ambient and forced vibration testing modules for the Bridge House has provided the students with a full-scale real-world structural dynamics laboratory where they can put their structural theory and modeling skills to the test. By physically testing the building structure, the students were able to compare the predictions of their models and make more intelligent decisions regarding the appropriateness of the model. As the students walked through the structure and felt and measured the vibrations, they became fully engaged in the learning process. Dry concepts such as equivalent viscous damping and diaphragm flexibility were brought to life. Advanced students were particularly inspired by the damage detection and thermal effect modules. While some of the modules are likely to remain unique to the Bridge House, the basic experimental setup and learning modules can be readily transferred to any interested teacher. The ultra-low 
forced vibration technique has been successfully implemented on 14 low rise buildings and is applicable to the typical buildings found on most university campuses.

\section{References}

1. Allemang R. J. “The Modal Assurance Criterion (MAC): Twenty Years of Use and Abuse.” Sound and Vibration, 2003.

2. Chopra, A. K. "Dynamics of Structures, Theory and Applications to Earthquake Engineering, Third Edition." Pearson Prentice-Hall, New Jersey, 2007.

3. Davena, R., et al. "Bridge House.” California Polytechnic State University, San Luis Obispo, 1966. San Luis Obispo: Cal Poly SLO, 1966.

4. Foschaar, Jennifer C. “Ambient Vibrations of an Existing Structure.” Architectural Engineering Senior Project. California Polytechnic State University, San Luis Obispo, 2008.

5. McDaniel, C.C., Archer, G. "Developing a 'Feel' for Structural Behavior.” American Society for Engineering Education (ASEE) Annual Conference, 2009.

6. McDaniel, C.C., Archer, G. C. "Full-scale, Real-time Building Dynamics Laboratory." $9^{\text {th }}$ U.S. National and $10^{\text {th }}$ Canadian Conference on Earthquake Engineering, Earthquake Engineering Research Institute, 2010

7. McDaniel, C.C., Archer, G. C. "Improving Student Understanding of Structural Dynamics Using Full-scale, Real-time Excitation of Buildings.” American Society for Engineering Education (ASEE) Annual Conference, 2010.

8. Planas, B., et al. "Rehabilitation of the Bridge House.” Senior Project. California Polytechnic State University, San Luis Obispo, 2011. San Luis Obispo: Cal Poly SLO, 2011.

9. Ramos, P., “System Identification of a Long-Span Building Structure.” Master’s Thesis. California Polytechnic State University, San Luis Obispo, 2011

10. Rendon, Adam R., "Determination of the Modal Parameters of a Five Story Reinforced Concrete Structure Using Ultra Low Level Excitation and Computational Analysis.” Master’s Thesis. California Polytechnic State University, San Luis Obispo, 2013.

11. Roskelley, B.. “An Investigation of the Influence of Diaphragm Flexibility on Building Design Through a Comparison of Forced Vibration Testing and Computational Analysis”, Master’s Thesis, Architectural Engineering Department, California Polytechnic State University, San Luis Obispo, 2010. 